\title{
choer
}

\section{Impactos das políticas públicas de turismo e de regularização fundiária em Jericoacoara - Ceará}

\section{Solange Maria da Conceição dos Santos}

Doutoranda em Políticas Públicas - UECE

Mestra em Planejamento e Políticas Públicas - UECE

\section{Roselane Gomes Bezerra}

Doutora em Sociologia pela Universidade Federal - UFC

Professora do Programa de Pós-Graduação em Avaliação de Políticas Públicas (MAPP) - UFC

\section{Resumo}

Este artigo tem por objetivo analisar a implementação das políticas públicas de turismo e de regularização fundiária pelo poder público estadual a partir dos anos 1990 na Vila de Jericoacoara. O Estado do Ceará, visando a frear ou acabar com as transações ilegais de compra e venda de terras e, ao mesmo tempo, buscando garantir a propriedade aos reais posseiros e impulsionar o turismo na área, por meio do Instituto de Desenvolvimento Agrário do Ceará (Idace), iniciou a política pública fundamentada juridicamente na Lei Estadual n. 12.760/1997, destinada a regularizar as terras em Jericoacoara. Essa ação conferiu segurança jurídica aos investimentos realizados no setor turístico.

Palavras-chave políticas públicas; turismo; regularização fundiária; posse; propriedade.

\begin{abstract}
This article aims to analyze the deployment of public policies relating to tourism and land regularization by the state public power from the 1990s in the Jericoacoara Village. The State of Ceará, aiming to stop or end illegal transactions in land purchase and sale and, at the same time, seeking to guarantee possession to actual owners and to boost tourism in the area, through the Ceará Institute of Agrarian Development (IDACE), initiated the public policy by having Ceará State Law No. 12,760/1997 as a legal basis, whose purpose is regularizing land ownership in Jericoacoara. This action provided investments made in the tourism sector with legal certainty. From the program's onset to January $11,2016,608,228.765 \mathrm{~m}^{2}$ of area were distributed.
\end{abstract}

Key words public policy; tourism; land regularization; possession; property.

Conhecer: debate entre o público e o privado

2018, Vol. 08, nำ 21

ISSN 2238-0426

DOI 10.32335/2238-0426.2018.8.21.1069

Licença Creative Commons Atribuição 


\section{Introdução}

A paisagem urbana da Vila de Jericoacoara se apresenta, à primeira vista, como um lugar cercado por campos de dunas, com brisa, sol, praia rochosa e arquitetura rústica, remetendo à ideia de praia preservada, com hotéis e pousadas de fachadas luxuosas, marcada pelas várias línguas distintas ouvidas ao caminhar por suas ruas e seus becos assimétricos e tortuosos (ora estreitos, ora largos), sem pavimentação - longe, portanto, das lembranças narradas por antigos pescadores, moradores e turistas que descrevem suas aventuras e histórias de vida na chamada Jeri de antes do advento do turismo.

A arquitetura paisagística do local passou a ser construída nos anos 1980, com a criação da área de proteção ambiental (APA), que atrelou a ideia de paisagens naturais à ideia de preservação ambiental mediada pelo turismo. Jeri, como é carinhosamente conhecida, deixou de ser uma comunidade de pescadores e tornou-se um dos destinos turísticos mais procurados do Ceará; seu espaço se tornou mercadoria, vendida como cenário por meio de marketing intenso pelo chamado "Governo das Mudanças". Segundo Nogueira (2016, p. 101), "Jericoacoara não é mais visitada, mas sim comprada como espaço de alegria, de lazer e oportunidade de um bom negócio”, sendo transportada nas imagens captadas pelos turistas de todo o mundo.

Esse processo se encontra relacionado com o turismo. Os nativos que haviam saído do local em busca de trabalho começam a retornar em busca das melhores oportunidades econômicas trazidas por essa atividade. Os visitantes que se encantavam com o local acabaram fixando residência e outros compraram a posse dos nativos e delegaram a estes a guarda até seu retorno; não raro, quando voltaram, o que havia sido adquirido já estava em posse de outras pessoas, assim, começaram a surgir conflitos relativos à posse da terra, acirrados pela disputa na aquisição de imóveis para a construção de hospedagens e restaurantes voltados à crescente atividade econômica do turismo.

Para fomentar a atividade turística, constatando o ambiente inseguro para o investidor, o Governo do Estado do Ceará deu início na Vila de Jericoacoara, na década de 1990 - por meio da Lei Estadual n. 12.760 (1997) e do Decreto Estadual n. 24.881 (1998), com apoio técnico do Instituto do Desenvolvimento Agrário do Ceará (Idace) e da Superintendência Estadual do Meio Ambiente (Semace) -, à política pública de regularização fundiária, a priori buscando legitimar a posse dos habitantes e promover a urbanização do local sem recorrer à remoção da população para outras localidades.

\section{Área do estudo - Vila de Jericoacoara}

A Vila de Jericoacoara se localiza no norte do Município de Jijoca de Jericoacoara, situado na costa oeste do Estado do Ceará (Costa Sol Poente), a aproximadamente 300 
km de distância da capital, Fortaleza. Tem como atrativo turístico a chamada "Rota das Emoções", que integra 14 municípios, nos estados do Ceará, do Piauí e do Maranhão. Sua paisagem natural apresenta cordões de dunas móveis, coqueirais, manguezais, restingas e diversas formações geológicas de grande potencial paisagístico e científico, que abrigam espécies raras da fauna e da flora. Em seu entorno se encontra o Parque Nacional de Jericoacoara (Parna) ${ }^{1}$, área de proteção permanente (APP), administrada e fiscalizada pelo Instituto Chico Mendes de Conservação da Biodiversidade (ICMBio).

Figura 1. Pedra Furada: Cartão Postal de Jericoacoara.

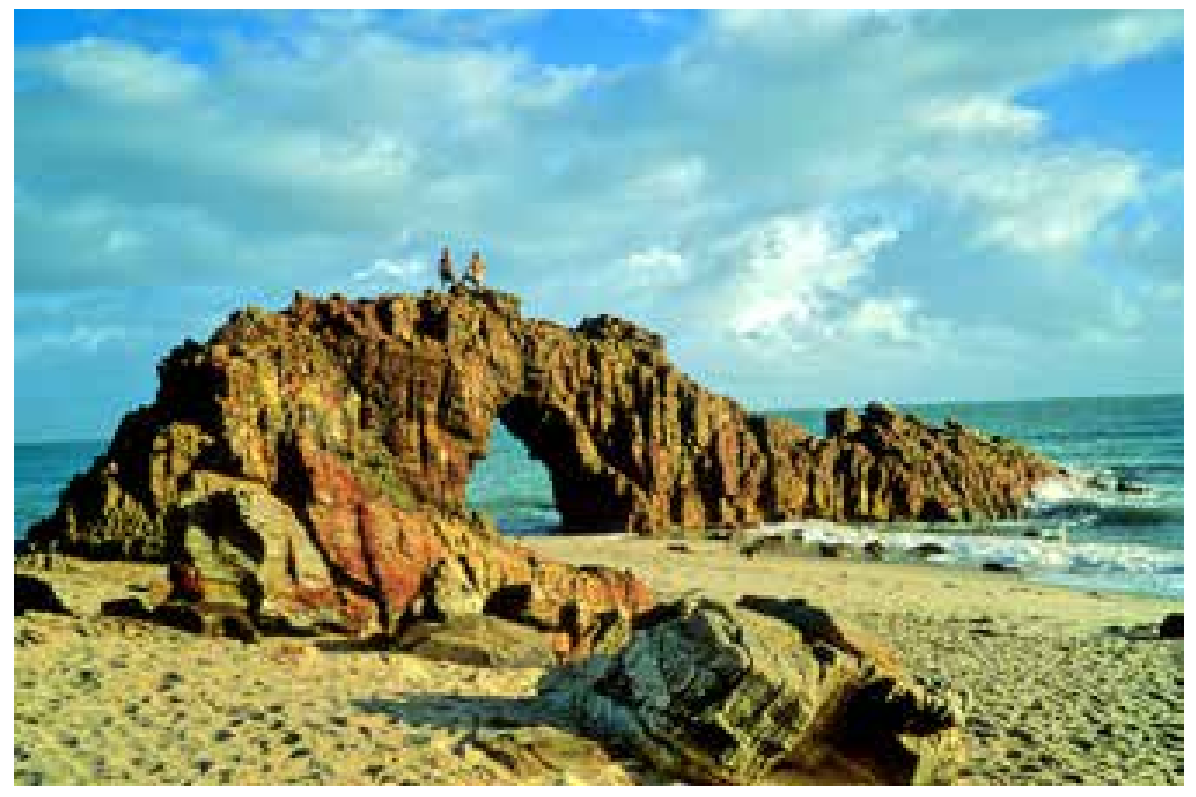

Fonte: ItamaratyGovBr

Jericoacoara se destaca como um dos principais destinos turísticos do Ceará e tem sido amplamente divulgada entre os roteiros turísticos nacionais e internacionais. Em 2016, foi eleita destino número 1 da América do Sul e garantiu o terceiro lugar no prêmio "Choice Awards Travelers", promovido pelo maior site de reservas do mundo, o TripAdvisor, que avaliou 43 destinos no mundo, selecionados pelo aumento das avaliações positivas de hospedagens, restaurantes e atrações turísticas locais (O Povo Online, 2016).

Sua inserção na rota internacional aguçou o olhar para o potencial turístico local, atraindo diversas pessoas de múltiplas nacionalidades que ali se instalaram - algumas em busca de uma vida sossegada. Fonteles (2000, p. 38) narra que "no final de 1989,

1 Localizado no Ceará, foi criado em fevereiro de 2002, com área de 8.416 ha, a partir da recategorização parcial da APA criada em 1984. Seus limites foram redefinidos em junho de 2007. 
Jericoacoara contava com aproximadamente 650 moradores nativos que se definiam como única família descendente de poucos patriarcas originais lá estabelecidos no início do século XX".

Antes do turismo, os nativos só conheciam a pesca, o companheirismo, a vida pacata; segundo o Núcleo de Geografia Aplicada (Nuga) (Universidade Estadual do Ceará [UECE], 1985, p. 101), não havia "acentuadas divisões de classes, com uma população de características particulares e homogêneas nas suas atividades, que estavam voltadas para o extrativismo [e a] pesca", além do comércio, da criação de rebanhos, da lavoura de subsistência e do artesanato, que se apresentavam como atividades secundárias.

\section{A Vila de Jericoacoara sob ação das políticas públicas}

As funções estatais sofreram inúmeras transformações com o passar dos tempos; nos séculos XVIII e XIX, seu principal objetivo era a segurança pública e a defesa externa em caso de ataque inimigo (visão liberal), atualmente, afirma-se que a função do Estado é promover o bem-estar da sociedade. Para tanto, necessita desenvolver uma série de ações, metas e planos para atuar diretamente em diferentes áreas, tais como saúde, educação, meio ambiente, reforma fundiária e turismo.

Essa atuação do Estado se mostra necessária, uma vez que a modernidade fez emergir as questões das classes sociais, das associações, das organizações e dos movimentos, que representam os interesses de cada grupo social (Henz \& Anjos, 2014, p. 4), fazendo com que a vida em sociedade seja complexa e frequentemente envolva conflitos: de opinião, de interesses, de valores etc.

Entretanto, o Estado atua a partir de diferentes influências territoriais que interferem no planejamento e na criação de políticas públicas específicas para cada uma das áreas demandadas (Henz \& Anjos, 2014, p. 7).

Ao definir políticas públicas, Dias (2003, p. 121) afirma que elas constituem um "conjunto de ações executadas pelo Estado, enquanto sujeito, dirigidas a atender às necessidades de toda a sociedade". São formadas por "linhas de ação que buscam satisfazer ao interesse público e têm que estar direcionadas ao bem comum”. Assim, as políticas públicas refletem, a um só tempo, pensamento e ação do governo em favor do bem coletivo.

Souza (2006, p. 26) afirma que "políticas públicas, após desenhadas e formuladas, desdobram-se em planos, programas, projetos, bases de dados ou sistema de informação e pesquisas. Quando postas em ação, são implementadas, ficando daí submetidas a sistemas de acompanhamento e avaliação".

Rua e Romanini (2013, p. 1) explicam que "as políticas públicas são resultantes das atividades política: compreendem o conjunto das decisões e ações relativas à alocação imperativa de valores". 
Nesse sentido, depreende-se que o Estado atua, de modo imperativo, valendo-se de um arcabouço jurídico próprio, assim, diversos atores podem estar envolvidos, em maior ou menor grau, nas diversas fases e atividades da política pública, mas seu envolvimento depende de decisões indispensáveis do Estado - que podem advir de diversos instrumentos, a legislação vigente ou a criação de leis e normas (Plano Plurianual - PPA; Lei de Diretrizes Orçamentárias - LDO; Lei Orçamentária Anual - LOA; decretos, regulamentos etc.) - para a construção de estadas, posto de saúde, fiscalização, regulação, mídias, transferência de renda (Bolsa Família, Programa Universidade para Todos - ProUni), incentivos fiscais (redução de Imposto sobre Produtos Industrializados - IPI, para fomentar as vendas da indústria) etc.

Governos interessados em promover o desenvolvimento socioeconômico regional e local entendem que o turismo pode ser um poderoso aliado na concretização de seus objetivos. Nesse contexto, tornou-se "objeto de desejo" de muitos gestores em diversas regiões.

A atividade econômica do turismo representa um conjunto de atividades produtivas que interessa a todos os setores econômicos de um país ou de uma região e é considerada uma força econômica das mais importantes do mundo, pois estimula fenômenos de consumo, originando renda e potencializando mercados onde a oferta e a procura se encontram, enfim, repercute em outros setores da economia, provocando uma reação em cadeia que causa um efeito multiplicador e influencia o emprego, a renda, a indústria e o comércio.

O turismo se torna atrativo para os governantes e as demais autoridades responsáveis pelo planejamento e a implantação de políticas públicas, que visam ao desenvolvimento regional. Entretanto, apesar da atividade gerar benefícios na comunidade, pode, em virtude de crescimento desordenado, provocar efeitos mais nocivos do que benéficos.

Coriolano e Silva (2005), na mesma linha de pensamento, advogam que o turismo é "uma atividade que implica o consumo dos espaços com diversidade de formas de utilização de paisagens e de negócios" e "quando realizado de acordo com o modo capitalista abusivo de exploração do trabalho, oferece respostas compatíveis com o que se propôs: moderniza, tecnifica, instrumentaliza e faz acumular e concentrar riqueza” (CORIOLANO, 2006, P.220). Já Coriolano, Araújo e Vasconcelos (2009, p. 76) afirmam que:

É claramente uma mercadoria capitalista, movimenta os fluxos humanos ou turísticos, transformando o real por meio de representações. A cidade dos turistas não é mesma dos residentes, revelando as contradições da sociedade de consumo. 
Todavia, embora a atividade turística possa representar uma excelente alternativa para o desenvolvimento local e/ou regional, faz-se necessário avaliar seus aspectos negativos, como os impactos no meio ambiente, na identidade local e nos patrimônios (natural e cultural), de modo a criar políticas públicas capazes de minimizar os danos e promover a melhoria da qualidade de vida da comunidade receptora, privilegiando a questão social e tornando a questão econômica uma consequência em vez de uma causa.

Nesse contexto, visando a fomentar a atividade turística, o Governo do Estado do Ceará, deu início na Vila de Jericoacoara, na década de 1990 - por meio da Lei Estadual n. 12.760 (1997) e do Decreto Estadual n. 24.881 (1998), com apoio técnico do Idace e da Semace -, à política pública de regularização fundiária, a priori buscando legalizar a posse dos habitantes e promover a urbanização do local, a fim de criar a infraestrutura necessária para atender à demanda turística.

O termo regularização fundiária vem, ao longo do tempo, assumindo significados diferentes e conceitos mais abrangentes, sofrendo uma evolução em sua compreensão como política pública. Mais do que simplesmente regularizar o terreno para determinados fins, em seu sentido mais original, cobre diversas dimensões (Cardoso, 2010). Esse termo é utilizado para designar a atuação destinada a revestir de maior proteção a posse sobre determinado imóvel. Isso pode ocorrer mediante a instituição de um título de propriedade ou de outro direito real. Oliveira (2001, p. 41) apresenta a seguinte definição:

A regularização fundiária é o procedimento pelo qual se busca tornar lícita, isto é, amparada pelo Direito, a ocupação da terra nos casos em que o acesso àquele bem tenha ocorrido de modo irregular.

Nesse diapasão, o aspecto jurídico visa a atribuir o domínio ou a posse da terra, de modo a conferir segurança aos ocupantes de terras que legalmente não lhes pertencem. Dentre os autores pertinentes, destaca-se Alfonsin (2007, p. 78), que apresenta uma definição clássica de regularização fundiária plena no âmbito do direito urbanístico:

Regularização fundiária é um processo conduzido pelo poder público e população beneficiária, envolvendo as dimensões jurídica, urbanística e social de uma intervenção que, prioritariamente, objetiva legalizar a permanência de moradores de áreas urbanas ocupadas irregularmente para fins de moradia e, acessoriamente, promove melhorias no ambiente urbano e na qualidade de vida do assentamento, bem como incentiva o pleno exercício da cidadania pela comunidade sujeito do projeto. 
Gonçalves (2009, p2) afirma que regularização fundiária consiste em "regularizar a posse dos habitantes e promover a urbanização do local sem recorrer à remoção da população para outras localidades; com frequência, o termo se limita à transferência de títulos fundiários, sobretudo os de propriedade privada."

Entende-se, a priori, que a regularização fundiária deve ser uma política pública que contribua para beneficiar a comunidade onde será implantada, devendo ser construída por meio de ações que possibilitem o controle e a participação dos membros interessados e executada de forma sustentável ambiental, econômica e socialmente, de modo justo e transparente, a fim de obedecer aos ditames da função social da propriedade, bem como de legitimar a propriedade da terra para seus reais donos.

O Governo do Estado do Ceará promoveu a regularização fundiária em Jericoacoara a partir da arrecadação das terras devolutas ${ }^{2}$ e seus respectivos registros em cartório. Esse processo contemplou o levantamento dos lotes, o cadastramento dos detentores, o reconhecimento da posse, e por fim, a distribuição dos títulos de propriedade.

Nesse sentido, Diniz (2009, p. 38) advoga que o instituto da posse se encontra definido de forma indireta no Código Civil de 2002 (Lei n. 10.406, 2002), por meio do conceito de possuidor elencado no art. 1.196; assim, afirma a autora: "vê-se que 'a posse' é o exercício, pleno ou não, de fato dos poderes constitutivos do domínio ou somente de alguns deles, como no caso dos direitos reais sobre coisas alheias".

Como prevê o art. 1.200 do Código Civil de 2002 (Lei n. 10.406, 2002), "é justa a posse que não for violenta, clandestina ou precária". Nos ensinamentos de Gonçalves (2009, p. 66), a posse "é aquela isenta de vícios, aquela que não repugna ao direito, por ter sido adquirida por algum dos modos previstos na lei, ou, segundo a técnica romana, a posse adquirida legitimamente, sem vício jurídico externo".

O modo de aquisição da posse pode ser originário, aquele que independe da anuência do antigo possuidor, segundo Diniz (2009, p. 67), ou derivada, que requer a existência de uma posse anterior e é transmitida ao adquirente, em virtude de um título jurídico, com a anuência do possuidor primitivo, sendo, portanto, bilateral.

Em se tratando do instituto jurídico da "propriedade", Locke (2001, p. 156) entende que cabe ao Estado, como organização civil, a função de proteger a propriedade em suas variadas facetas: "a preservação da propriedade é o objetivo do governo, e a razão por que o homem entra na sociedade". O cerne do conceito de propriedade do autor se baseia no direito natural, assim como o direito à vida e o direito à liberdade.

No Código Civil de 2002 (Lei n. 10.406, 2002), considera-se proprietário aquele com a faculdade de usar, gozar e dispor da coisa, além do direito de reavê-la do poder de quem quer que injustamente a possua ou detenha.

2 Áreas sem destinação pública, ou seja, não se encontram destinadas a uso específico pelo poder público e que não estão integradas ao patrimônio do particular. 
Fazendo a distinção entre posse e propriedade, pode-se inferir que esta é uma situação de direito, ancorada na lei, e a aquela é uma situação de fato, protegida pela lei. Perde-se a posse quando cessa, mesmo contra a vontade do possuidor, o poder sobre o bem. Já a propriedade se perde por alienação, pela renúncia, por abandono, por perecimento e por desapropriação.

\section{Turismo: imagens, conflitos e inovações na Vila de Jericoacoara e em seu entorno}

O turismo depende fundamentalmente de espaços turísticos, que são notadamente de duas dimensões: espaços-natureza e espaços-patrimônio. Nos espaços-natureza, como a Vila de Jericoacoara, tanto praias como montanhas e parques naturais são áreas predominantemente ocupadas por populações de pescadores artesanais, no caso das áreas litorâneas, e por agricultores e coletores que praticam uma agricultura de subsistência, no caso das áreas naturais e montanhas. Em ambas as situações, o comum é que os grandes investidores, quando não o próprio Estado, promovam o deslocamento forçado das populações que residem nessas áreas turísticas (Rodrigues, 2015, p. 84).

A combinação entre natureza e turismo atrelada à imagem de Jericoacoara, como em outras localidades, aguçou o olhar do mercado imobiliário. Nessa linha de pensamento, Coriolano (2006, p. 159) afirma:

\footnotetext{
Existe no litoral uma forte disputa de terras. Este espaço foi ocupado tradicionalmente pelas chamadas comunidades nativas [...] que foram pressionadas a vender suas propriedades para a instalação dos equipamentos turísticos, hotéis, resorts, parques aquáticos. Enquanto o litoral constituía apenas uma reserva de valor, essa ocupação tradicional pelas comunidades pesqueiras era mais pacífica, contudo, com a descoberta do litoral para o lazer e o turismo, acelerou-se o processo de expulsão de nativos e expropriação de terras para as segundas residências e para o turismo, desrespeitando o direito das comunidades tradicionais.
}

A construção da imagem turística da Vila de Jericoacoara se iniciou nos anos 1980 e foi intensificada a partir de então por políticas públicas estaduais que visavam a tornar o estado um polo receptor de turismo. Segundo Nogueira (2016, p. 79-80) o "Estado ao lado da iniciativa privada são os maiores produtores da imagem que vende a vila" desde 1984, com a criação da APA, a produção das mídias atrelava a paisagem natural da vila à ideia de 
proteção ambiental. Em 1986, a Rede Globo de Televisão, por meio do programa Fantástico, exibiu uma reportagem divulgando a praia de Jericoacoara (Coriolano, 2006).

Esse marketing atraiu turistas, segundo Fonteles (2000, p. 149), e esse aumento de fluxo turístico, nacional e internacional, tornou-se incompatível com a infraestrutura local, "trazendo problemas à população receptora, desequilibrando os ecossistemas, criando um turismo desordenado, comprometendo a qualidade de vida dos moradores". O autor cita diversas manchetes de jornais que divulgaram Jeri na época, por meio de "textos e fotografias de paisagens encantadoras, convidativas para quem deseja visitar ambientes naturais e bucólicos" (Fonteles, 2000, p. 163).

A pequena Vila de Jericoacoara, constituída por casas de taipas e pedra, com jangadas à beira-mar passou por um processo de transformação com a chegada do turismo: seu espaço foi moldado, planejado para atender aos interesses de grupos e frações de classes que se apropriaram privadamente de seus espaços. Sua imagem foi produzida para atender aos interesses do capital, utilizando um forte apelo de marketing por parte do governo estadual e dos empresários estrangeiros e nacionais dos ramos de serviços e comércio.

O espaço social da Vila de Jericoacoara é um produto social. O cotidiano é construído dia a dia, a própria arquitetura e urbanização sofreram grandes alterações desde a chegada do turismo. As relações de sociabilidade dos nativos entre eles e com os demais habitantes (estrangeiros ou turistas) são trabalhadas no cotidiano e, concomitantemente, há atuação da força política, do capital privado e do Estado, que visam a dominar o espaço. Jericoacoara não se comporta somente como um lugar de consumo de produtos, mas como um lugar de consumo de imagem, fundamental para uma cidade que depende do turismo e o tem como principal atividade econômica.

A orla passou a ser ocupada por hotéis luxuosos, que disputam espaço com a paisagem natural do lugar. O site TripAdvisor (n.d.) apresenta 6 hotéis de luxo na vila, todos localizados na orla: Pousada Vila Kalango; Hotel Hurricane Jeri; Essenza Hotel; Blue Residence Hotel; The Chili Beach Boutique Hotel \& Resort; e Hotel Casa de Areia.

Em decorrência da valorização da terra surgiu a especulação imobiliária, que Novaes (1987 como citado em Fonteles, 2000, p. 181) identificou em Jericoacoara como consequência de dois tipos de ação:

1. Turista que compra e destrói o barraco do pescador no centro da vila, para construir a sua casa de temporada; 2 . Chegada de pessoas de fora de Jericoacoara que receberam terras como herança; constroem casas, algumas para temporada, e consideram-se nativos. 
Molina (2007, p. 6) narra que boa parte dos moradores nativos venderam suas terras aos donos de pousadas e restaurantes e deslocaram-se para uma área mais afastada da vila, formando uma favela, conhecida como "Nova Jeri”. Depreende-se que os preços dos imóveis influenciam o deslocamento da população para as zonas periféricas do lugar, gerando conflitos e invasões irregulares ${ }^{3}$. Fonteles (2000, p. 185) ${ }^{4}$ afirma que não existia entre os nativos um consenso sobre as questões de compra e venda de lotes, "para uns, a venda da terra se fez necessária para que pudessem melhorar a sua casa e receber o turista. Para outros, a questão é problemática e preocupante".

Caminhando pelas ruas e becos é possível encontrar várias placas de "vende-se" ou "aluga-se" e os preços dos imóveis variam conforme a localização: quanto mais próximos à praia e à Rua Principal, mais valorizados são, como narrou o corretor local.

Os hotéis de luxo e os restaurantes, localizados especialmente na orla, estão concentrados nas mãos de empresários que chegaram em Jeri desde antes do turismo de massa. Muitos vieram e apaixonaram-se pelo local, compraram as terras dos antigos pescadores e, dotados de visão empresarial, começaram a explorar a área construindo pousadas e/ou restaurantes.

Tais construções destoam da realidade do lugar; um exemplo é a "Nova Jeri", ocupada de forma desordena em decorrência do valor de aquisição da terra. Nessa zona periférica estão localizados os equipamentos públicos (creche, escola, unidade de pronto atendimento - UPA). As casas são simples, sem muita estrutura, salvo algumas exceções - que dão sinais de que o turismo, aos poucos, também está se apropriando dessas áreas. Muitos imóveis são destinados para aluguel e empregados das pousadas e hotéis - o valor relativo a um quarto e sala passa de $\mathrm{R} \$ 1.000,00$.

Com o turismo, os imóveis passaram a ter maior procura, expulsando os moradores para as áreas periféricas. Muitos moradores venderam suas propriedades na área central e migraram para outras comunidades; outros passaram a residir na Sede de Jijoca de Jericoacoara ou mudaram para Camocim, abrindo mão de seu espaço natural para dar lugar aos empreendimentos turísticos.

Outros que chegaram, sem condições de alugar ou comprar um imóvel para servir de moradia, dado o elevado custo de vida, passaram a construir ou invadir áreas públicas

3 Em 2014, cerca de 200 pessoas invadiram uma área pertencente ao Governo do Estado do Ceará, destinada a abrigar escolas, praças e até uma unidade de pronto atendimento (UPA). Esse fato foi noticiado na impressa e detalhado no blog Sobral Notícias (2014), o Conselho Comunitário se pronunciou contra as invasões, afirmando que "a população, inclusive nativos, se revoltou porque as pessoas de fora vinham e construíam em Jeri como invasores e a própria população não pode" (Diário do Nordeste, 2014). Segundo a reportagem, o Deputado Estadual João Jaime afirmou que "são pessoas que vieram de fora e não fazem parte da comunidade" (Diário do Nordeste, 2014).

4 Há relatos completos dos moradores em Fonteles (2000, p. 185). 
no entorno da Vila de Jericoacoara - a exemplo das construções irregulares no Parna ou na Nova Jeri.

\section{Requalificação e regularização fundiária}

Visando a diminuir os conflitos, impulsionar o desenvolvimento turístico e evitar a degradação ambiental o Governo do Estado do Ceará iniciou o processo requalificação da Vila de Jericoacoara em abril de 2002, com licença para construção emitida pela superintendência estadual do Instituto Brasileiro do Meio Ambiente e dos Recursos Naturais Renováveis (Ibama), tendo como objetivo geral o ordenamento, a estruturação e a requalificação do espaço urbano da vila, visando à sua consolidação como polo de turismo. Molina (2007, p. 11) descreve:

\footnotetext{
No intuito de incrementar a atividade turística, o governo estadual, juntamente com investimentos estrangeiros, criou, em 1999, o Plano Diretor de Jericoacoara, e um dos desdobramentos deste plano é o Projeto de Requalificação Urbana da Vila de Jericoacoara, que previa a construção de um centro cultural e de turismo, um mercado público, creche, oficina de artesanato, centro esportivo, posto de saúde, posto policial, parque do cemitério, quiosques e serviços de terraplanagem, urbanização, paisagismo, sinalização de vias, estacionamento, além também de dar início à licitação para a implantação do sistema de esgotamento sanitário de Jericoacoara.
}

A criação do Plano Diretor, em 1999, visou a fomentar a atividade turística e teve como desdobramento o Projeto de Requalificação Urbana da Vila de Jericoacoara, prevendo a construção de equipamentos e serviços públicos, como a construção do mercado público, da creche, do posto de saúde, do posto policial, do parque do cemitério, além da urbanização, do paisagismo, da sinalização de vias e do estacionamento.

Essa política foi o embrião para a expansão do espaço urbano, dando os primeiros sinais de crescimento territorial em função do crescimento da atividade do turismo; os imóveis passaram a ter maior procura, entretanto, a transação não tinha segurança jurídica, as narrativas dos nativos dão conta de que, não raro, o mesmo terreno era vendido mais de uma vez, principalmente para os estrangeiros que se encantavam com o local.

Concomitantemente ao processo de requalificação, o governo estadual, visando a frear ou acabar com as transações ilegais de compra e venda de terras e, ao mesmo tempo, buscando garantir a propriedade aos reais posseiros e impulsionar o turismo na área, por meio do Idace, adotou ações para criar uma política pública - fundamentada juridicamente 
na Lei Estadual n. 12.760 (1997) e regulamentada pelo Decreto Estadual n. 24.881 (1998) destinada a regularizar as terras em Jericoacoara.

O primeiro procedimento administrativo realizado pelo Governo do Estado do Ceará foi a busca em cartórios da região (Acaraú e Camocim, entre outros), para identificar em nome de quem estava registrada a propriedade da área. Esse procedimento teve início a partir do Processo Administrativo n. 95076047-1/95, como consta no primeiro "considerando" da Portaria Estadual n. 451 (1997):

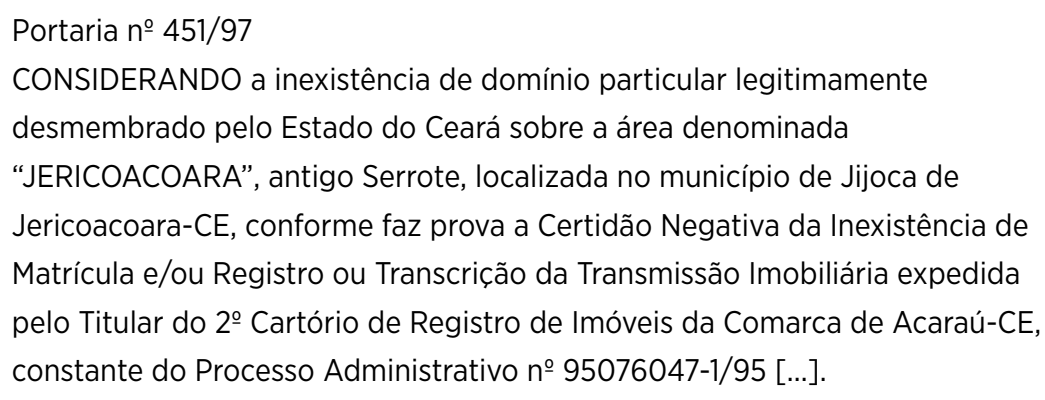

Finalizadas as buscas, concluiu-se que os imóveis existentes na Vila de Jeri não tinham documentos de propriedade ${ }^{5}$, todos os que se diziam proprietários eram na realidade posseiros, inclusive os não nativos (nacionais e estrangeiros) que haviam comprado lotes dos nativos, em virtude da posse se transmitir aos herdeiros ou legatários do possuidor com os mesmos caracteres.

Assim o Estado "arrecadou" esses imóveis e registrou-os no Cartório de Registro de Imóveis da Comarca de Acaraú, sob a Matrícula n. 2.338, Livro 2-H, folhas 274, em 8 de outubro de 1997, como terras devolutas ${ }^{6}$, como se verifica aqui:

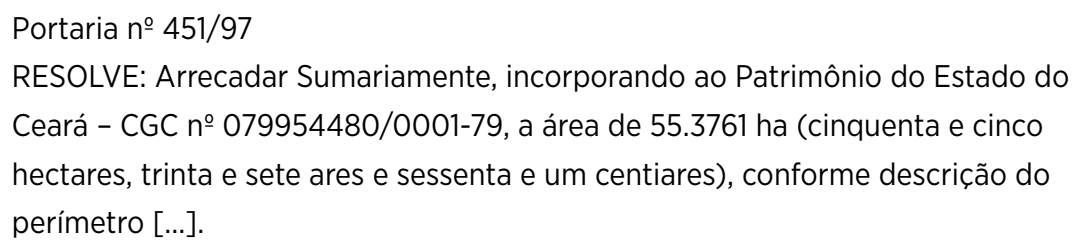

Todas as áreas registradas nos órgãos competentes como de propriedade de terceiros foram preservadas e reconhecidas. No mesmo ano, já com o registro de propriedade das

\footnotetext{
$5 \quad$ Para a distinção entre posse e propriedade, ver p. 77.

$6 \quad$ Para consultar as definições, ver p. 73.
} 
terras, o Governo do Estado do Ceará iniciou a Política Pública de Regularização Fundiária na Vila de Jericoacoara, por meio da Lei Estadual n. 12.760 (1997), que dispõe:

\begin{abstract}
Art. 1ำ Fica autorizada a alienação, a qualquer título, do imóvel pertencente ao patrimônio do Estado do Ceará localizado no Município de Jijoca, denominado JERICOACOARA, antigo SERROTE, com área de 55.3761 ha [...], adquirido em 08 de outubro de 1997, objeto da matrícula no 2.338, Livro 2-H às fls. 274 do Cartório de Registro de Imóveis da Comarca de Acaraú-CE.
\end{abstract}

Em 24 de abril de 1998, o Ceará regulamentou a Lei Estadual n. 12.760 (1997), por meio do Decreto Estadual n. 24.881 (1998), estabelecendo procedimentos visando à regularização fundiária e alienação das terras.

No corpo do Decreto Estadual n. 24.881 (1998), art. 5, caput e incisos, são estabelecidos os critérios e as regras para a legitimação da posse, dentre elas:

1. As ocupações deveriam ser mansas e pacíficas (art. $5^{\circ}$ );

2. Os ocupantes de uma só posse ou aqueles que possuíam duas ou mais, sendo uma "para moradia e as demais destinadas a quaisquer outras atividades", teriam a posse de morada regularizada sem ônus, desde que, a "renda familiar" anual não fosse superior a 25 (vinte e cinco) salários mínimos e que estivesse na "posse mansa e pacífica" há pelo menos 5 (cinco) anos, "por si ou por seus antecessores (inciso I); 3. Os posseiros de imóveis (pessoas físicas ou jurídicas) que "não se destinavam para moradia permanente e direta do detentor e sua família" para efeito de regularização deveriam efetuar pagamento ao "Estado do valor de mercado da terra nua" (inciso II). Em se tratando de pessoa jurídica, antes da alienação deveria apresentar Certidão Negativa de Débitos estadual (inciso III). Sendo pessoa física, teria direito de preferência desde que os imóveis, objeto de posse, estivessem "destinados a atividades econômicas ou de lazer" (inciso IV);

4. As áreas que não ocupadas, seriam alienadas por meio de procedimento licitatório (inciso V), em virtude de serem bens de propriedade do Estado e para que sejam alienadas se faz necessário obedecer ao processo de licitação, cujo regramento se encontra disposto na Lei Federal n. 8.666/1993;

5. O último inciso (VI) delega a Comissão Especial a apreciação e a decisão dos casos não contemplados no decreto.

Frisa-se que, como disposto no art. 2ํㅡㄹ criou-se uma Comissão Especial, sob a coordenação do Idace, com a participação da Semace, para "proceder aos atos de regularização e alienação das terras". Ao Conselho Comunitário, por meio do Comitê de Acompanhamento, caberia referendar ou não, de acordo com o caso concreto, o reconhecimento das posses aos detentores. 
Ressalta-se, ainda, que recorrendo à metodologia para revisar/aprovar/reprovar, bem como ao critério de seleção dos beneficiários adotado, não foi possível obter maiores informações do Idace, apesar das várias tentativas realizadas com a finalidade de obter acesso às atas e aos documentos que embasaram o processo de regularização, o órgão alegou, via Diretor de Projetos, que as atas haviam sido extraviadas e que os arquivos se encontram em meio físico, o que dificulta muito o acesso ao acervo referente aos registros do cadastramento.

\section{Evolução quantitativa da distribuição dos títulos de reconhecimento de posse de 2001 a 2016 pelo Idace}

As relações elaboradas pelo Idace referentes aos dados cadastrais dos imóveis na Vila de Jericoacoara nos anos de 2005, 2007 e 2016 possibilitou uma projeção do número de títulos distribuídos desde o levantamento cadastral ocorrido no início do programa, em 2001, até o ano de 2016.

Outro dado relevante é que as relações elaboradas pelo Idace são acumulativas, ou seja, a cada publicação se incorporam novas áreas às já existentes nos anos anteriores, possibilitando uma análise com base nos novos dados inseridos a cada nova edição da relação.

Entre o início do programa de regularização fundiária com base na Relação Geral de Imóveis Urbanos e seus Detentores, de 2001, até o ano de 2005 ocorreu um aumento de $22 \%$ na Relação de Imóveis de Jericoacoara, passando de 515 detentores cadastrados para 662. Neste número estão inseridos os entes públicos que receberam lotes, assim como as instituições religiosas e o Conselho Comunitário de Jericoacoara.

Na relação de 2007 se verifica um acréscimo de 25 nomes, chegando a um total de 687 imóveis, e em 2016 esse número passou para 710 imóveis, ou seja, 195 lotes a mais distribuídos pelo Idace em relação a 2001. O Gráfico 1 representa a evolução na distribuição dos títulos de 2001 a 2016. 
Gráfico 1 - Evolução da distribuição dos títulos (2001-2016)

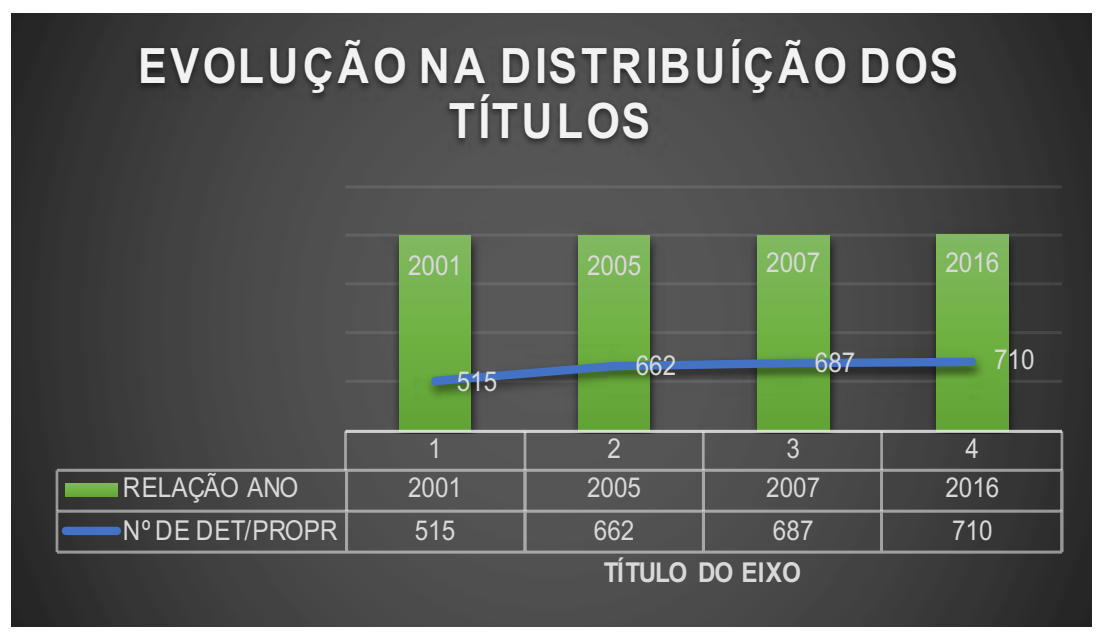

Fonte: Elaborado pelas autoras.

Outro ponto verificado: até 11 de janeiro de 2016 foram distribuídos 608.228,765 $\mathrm{m}^{2}$ de área. Comparando com a relação geral de 2001, verifica-se um aumento de aproximadamente $42 \%$ da área inicial.

Gráfico 2 - Área distribuída em m² (2001-2016)

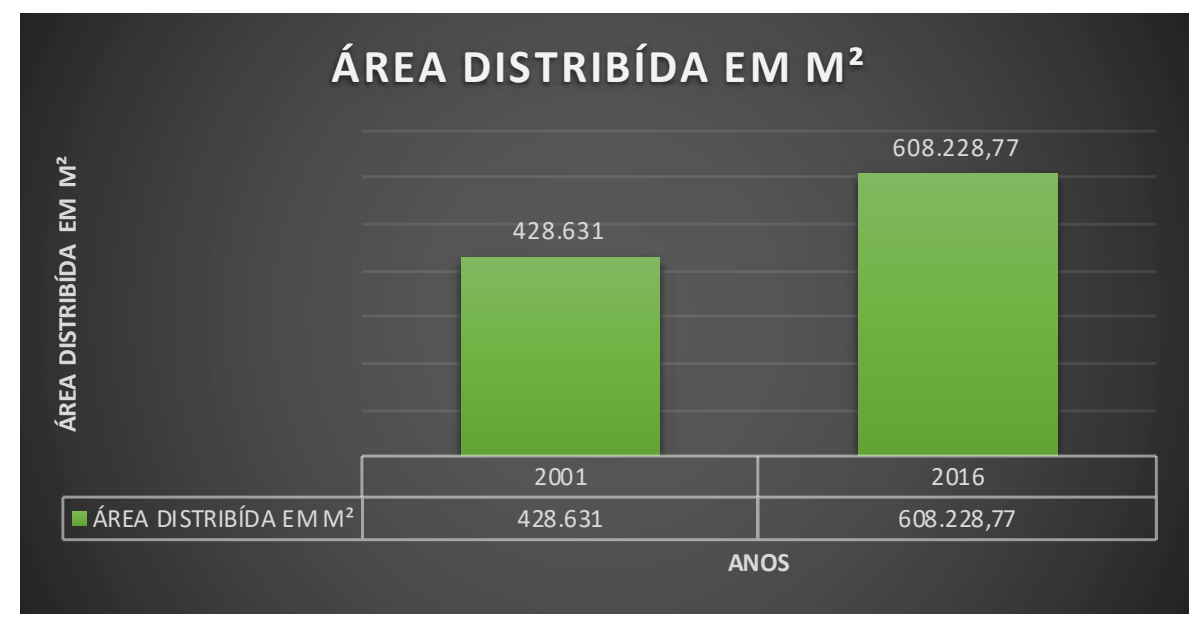

Fonte: Elaborado pelas autoras.

Entretanto, não foi possível analisar os critérios utilizados pelo Idace para o aumento de aproximadamente $37,5 \%$ do número da distribuição dos títulos, assim como o acréscimo 
de 53.352,484 $\mathrm{m}^{2}$ de área distribuída, isso sem contar com a área que ainda pertence ao governo estadual, a exemplo da UPA, que não aparece no documento analisado.

Os processos de arrecadação ${ }^{7}$ de terras realizados pelo Idace, entre 1997 e 2016, a área total perfaz $6.238,5571$ ha (seis mil, duzentos e trinta e oito hectares, cinquenta e cinco ares e setenta e um centiares). Contudo, de acordo com o art. 1ำ da Lei Estadual n. 12.760 (1997) ${ }^{8}$, a área autorizada para alienação era de 55,3761 ha, ou seja, 553.761 $\mathrm{m}^{2}$, como consta na primeira escritura pública de Matrícula n. 2.338, Livro 2-H, folhas 274 , registrada no Cartório de Registro de Imóveis da Comarca de Acaraú em 8 de outubro de 1997. Indague-se como foi possível distribuir 607.113,484 $\mathrm{m}^{2}$ conforme a relação de 2016 se a lei pertinente disponibilizou apenas $553.761 \mathrm{~m}^{2}$ ? Qual instrumento legal autorizou a ampliação? Quais estudos foram feitos? Qual regramento foi obedecido para a distribuição dos novos títulos? Qual é a área remanescente pertence ao Estado?

\section{Conclusão}

O turismo criou novas oportunidades de renda para os nativos de Jericoacoara, porém, gerou mudanças sociais, econômicas e culturais, sobretudo no espaço urbano, onde ocorreram os maiores impactos. O processo de requalificação, aliado ao processo de regularização fundiária, causou a expansão urbana, a implantação dos equipamentos públicos e o deslocamento da população para outras áreas, fazendo surgir, nos espaços periféricos, uma nova realidade, distinta daquela construída, produzida e vendida para o turismo. Assim, constata-se que no espaço urbano da Vila de Jericoacoara há duas realidades: a Jeri, conhecida internacionalmente e vendida como paraíso turístico; e a Nova Jeri, com seus conflitos socais e fundiários, aparentemente desiguais.

O processo de segregação socioespacial é nítido em Jeri e na Nova Jeri: as áreas mais próximas da orla da praia e do centro são mais valorizadas e mais bem cuidadas, priorizando-se os investimentos em infraestrutura básica e turística. O local se caracteriza, principalmente, por estabelecimentos comerciais voltados a atender aos turistas, além de possuir maior investimento em infraestrutura nas ruas em que há maior circulação de visitantes. Assim, a Jericoacoara conhecida internacionalmente possui ruas e becos

7 A primeira arrecadação, ocorrida em 08/12/1997, a área arrecadada foi de 55.3761 ha, conforme a Matrícula n.

2.338, Livro 2-H, folhas 274, registrada no Cartório de Registro de Imóveis da Comarca de Acaraú. A Segunda ocorreu em 31 de março de 2000, conforme Registro no Cartório Liberty Morais da Comarca de Jijoca de Jericoacoara, Matrícula 12, Livro 2-A, folhas $31 / 32$.

8 Art. 1ำ Fica autorizada a alienação, a qualquer título, do imóvel pertencente ao patrimônio do Estado do Ceará localizado no Município de Jijoca, denominado JERICOACOARA, antigo SERROTE, com área de 55.3761 ha [...], adquirido em 08 de outubro de 1997, objeto da matrícula nํ⒉338, Livro 2-H às fls. 274 do Cartório de Registro de Imóveis da Comarca de Acaraú-CE. 
voltados ao comércio turístico: pousadas, restaurantes, pizzarias, lanchonetes, sorveterias e lojas de conveniência, que convivem lado a lado, disputando espaço físico e ocupando espaço público a fim de alimentar toda a cadeia produtiva do turismo.

Na Nova Jeri, por sua vez, em zonas mais próximas ao centro da vila, as casas têm uma melhor estrutura, existem pequenos comércios voltados aos trabalhadores e nativos. $\mathrm{Na}$ região, próxima à entrada da vila, vizinha ao estacionamento, estão concentrados os equipamentos públicos municipais, observa-se uma zona mais esquecida pelo poder público e pela iniciativa privada. As casas, em sua maioria, são destinadas à moradia, pequenas áreas são alugadas e muitas delas foram ocupadas irregularmente - ou por caracterizarem invasão ou por terem sido ampliadas, passando a incorporar também o espaço público.

A atividade turística forçou ao Governo do Estado do Ceará a elaborar um programa de regularização fundiária, haja vista os conflitos relacionados à compra e venda irregular de terras, grilagens, especulação imobiliária, com o objetivo de fixar o nativo, mas, na realidade forneceu condições jurídicas aos empresários (brasileiros e estrangeiros) que haviam comprado a posse dos nativos a investirem no local. Com as terras regularizadas, os empresários investiram em infraestrutura voltada ao turismo, por exemplo: meios de hospedagem e restaurantes. O título de propriedade, distribuído pelo Idace, conferiu segurança jurídica para investir na atividade turística.

Outro aspecto a destacar é que a política pública de regularização não privilegiou os nativos, mas aqueles que comprovavam a posse da terra, sejam nativos, brasileiros ou estrangeiros. Estes, embora não nativos, permanecem até hoje com a propriedade e são os responsáveis, junto com os agentes públicos locais e estaduais, por divulgar Jericoacoara para o mundo, logicamente defendendo interesses próprios, com a intenção de obter lucro após os investimentos realizados. O poder econômico desses atores é tão forte que, não raro, interfere no poder político local. O Conselho Comunitário já não possui tanta força política, existem vários grupos organizados em Jericoacoara distribuídos em associações (transporte, crocheteiras, catadores, guarda-sol, empresários etc.) que buscam defender interesses próprios. Não existe um grupo coeso ou uma liderança política organizada, no sentido de reivindicar benefícios para a comunidade em geral, o que se verifica é que os interesses são de grupos e não coletivos.

Sugere-se que - em decorrência dos interesses envolvidos (terra, capital, poder) e visando a avaliar o programa de regularização fundiária implantada em Jericoacoara - o Governo do Estado do Ceará realize recadastramento da área e novo georreferenciamento, sobretudo por já terem passado 18 anos desde sua implantação. 


\section{Referências}

Alfonsin, B. (2007). O significado do Estatuto da Cidade para os processos de regularização fundiária no Brasil. In R. Rolnik (Org.), Regularização fundiária sustentável: conceitos e diretrizes (pp. 68-98). Brasília, DF: Ministério das Cidades.

Cardoso, B. K. (2010). Efeitos da regularização fundiária: estudo de caso em assentamentos precários de Santa Catarina (Dissertação de Mestrado). Universidade Federal de Santa Catarina, Florianópolis, SC.

Coriolano, L. N. (2006). O turismo nos discursos, nas políticas e no combate à pobreza. São Paulo, SP: Annablume.

Coriolano, L. N., Araújo, A. M. M., \& Vasconcelos, F. P. (2009). Arranjos produtivos locais do turismo comunitário: atores e cenário em mudanças. Fortaleza, CE: Ed. UECE.

Coriolano, L. N. \& Silva, S. B. M. (2005). Turismo e geografia: abordagens críticas. Fortaleza, CE: Ed. UECE.

Decreto Estadual n. 24.881. (1998, 24 de abril). Fortaleza, CE.

Diário do Nordeste. (2014, 21 de maio). Terrenos públicos são ocupados ilegalmente na Vila de Jericoacoara. Recuperado de http://diariodonordeste.verdesmares.com.br/editorias/regiao/terrenos-publicos-sao-ocupados-ilegalmente-na-vila-de-jericoacoara-1.1019456

Dias, R. (2003). Planejamento do turismo: política e desenvolvimento do turismo no Brasil. São Paulo, SP: Atlas.

Diniz, M. H. (2009). Curso de direito civil brasileiro: direito família (24a ed.). São Paulo, SP: Saraiva.

Fonteles, O. J. (2000). Jericoacoara: turismo e sociedade. Sobral, CE: Ed. UVA.

Gonçalves, C. R. (2009). Direito civil brasileiro (4a ed.). São Paulo, SP: Saraiva.

Gonçalves, Rafael Soares. Repensar a regularização fundiária como política de integração socioespacial. Estud. av., São Paulo, v. 23, n. 66, p. 237-250, 2009. Available from <http://www.scielo. $\mathrm{br} / \mathrm{scielo}$.php?script=sci_arttext\&pid=S0103-40142009000200017\&lng=en\&nrm=iso> . access on 27 Feb. 2019. http://dx.doi.org/10.1590/S0103-40142009000200017.

Henz, A. P., \& Anjos, F. A. (2014). A construção de políticas de turismo no Brasil: abordagens sobre estado, governo, políticas públicas e descentralização. In Anais do 110 Seminário Anual da Associação Nacional de Pós-Graduação em Turismo. Fortaleza, CE.

Lei n. 10.406. (2002, 10 de janeiro). Institui o Código Civil. Brasília, DF. Recuperado de http://www. planalto.gov.br/ccivil_03/LEIS/2002/L10406.htm

Lei Estadual n. 12.760. (1997, 4 de dezembro). Fortaleza, CE.

Locke, J. (2001). Segundo tratado sobre o governo civil e outros escritos: ensaio sobre a origem, os limites e os fins verdadeiros do governo civil (3a ed.). Petrópolis, RJ: Vozes. 
Molina, F. S. (2007). A produção do espaço pelo e para o turismo: o caso da praia de Jericoacoara, Ceará, Brasil. Recuperado de http://observatoriogeograficoamericalatina.org.mx/egal12/Geografiasocioeconomica/Geografiaturistica/25.pdf

Nogueira, D. S. (2016). A produção do espetáculo em Jericoacoara-CE (Dissertação de Mestrado). Universidade de São Paulo, São Paulo, SP.

Oliveira, I. C. E. (2001). Estatuto da Cidade: para compreender. Rio de Janeiro, RJ: Instituto Brasileiro de Administração Municipal.

O Povo Online. (2016, 7 de dezembro). Praia de Jericoacoara é eleita destino número 1 da América do Sul. Recuperado de https://www.opovo.com.br/noticias/brasil/2016/12/praia-de-jericoacoara-e-eleita-destino-numero-1-da-america-latina.html

Portaria Estadual n. 451. (1997, 21 de julho). Fortaleza, CE.

Rodrigues, L. C. (2015, abril). Turismo em espaços urbanos: processos de turistificação no Nordeste brasileiro e no Caribe mexicano. Revista Iberoamericana de Turismo, 2015(5), 81-104.

Rua, M. G., \& Romanini, R. (2013). Para aprender políticas públicas. Brasília, DF: Instituto de Gestão, Economia e Políticas Públicas.

Sobral Notícia. (2014, 21 de maio). Jeri invadida pede socorro. Recuperado de https://sobralnoticia. blogspot.com/2014/05/jeri-invadida-pede-socorro.html

Souza, C. (2006). Políticas públicas: uma revisão da literatura. Sociologias, 8(16), 20-45.

Uchôa, A. (n.d.). Banco de imagens de fotos do Brasil. Recuperado de http://www.pbase.com/alexuchoa

Universidade Estadual do Ceará. (1985). Área de Proteção Ambiental: Jericoacoara. Fortaleza, CE: Núcleo de Geografia Aplicada.

TripAdvisor. (n.d.). Hotéis de luxo: Jericoacoara. Recuperado de https://www.tripadvisor.com.br/ Hotels-g303297-zff12-Jericoacoara_Jijoca_de_Jericoacoara_State_of_Ceara-Hotels.html 